\title{
Technology Assessment: Tear gas safety and usage practices
}

\section{Jennifer L. Brown, Carey E. Lyons, Carlee Toddes, Timothy Monko, Roman Tyshynsky}

University of Minnesota, Graduate Program in Neuroscience, Minneapolis, MN

https://doi.org/10.38126/ISPG180104

Corresponding author: brow4706@umn.edu

Keywords: Tear gas; respiratory health; human exposure; demonstration control agent; COVID-19

Executive Summary: While the U.N. Chemical Weapons Convention bans tear gas and other chemical weapons from use in war, their use is still allowed in domestic policing. Public concern about tear gas utilization increases when social justice protesters are subjected to these chemical demonstration control agents. The history of tear gas utilization by law enforcement in the U.S. is rife with corruption and racist intent. Furthermore, the scientific evidence supporting the safety of tear gas is lacking due to both the misinterpretation of public health studies and the paucity of controlled experiments. We find that the current utilization of tear gas is a threat to public health, free speech, and possibly falls outside of the exception for domestic use. We discuss policy alternatives that include alternative crowd control methods, changes to protocols for tear gas deployment and post-use review, increased regulatory oversight, and the possibility of a complete tear gas ban.

\section{Introduction}

Tear gas has long been used as a method of crowd control in the U.S., and its use in 2020 was especially prevalent (Lai, Marsh, and Singhvi 2020). Though banned from use in war by the 1925 Geneva Protocol (Protocol for the Prohibition of the Use in War of Asphyxiating, Poisonous or Other Gases, and of Bacteriological Methods of Warfare (Geneva Protocol) 1925; "Customary IHL - Practice Relating to Rule 75. Riot Control Agents" 1993), the use of chemical demonstration control agents (DCAs) is not prohibited in domestic policing. Despite its widespread use in this capacity, there is a scarcity of information regarding the long-term effects of tear gas on human health and on the environment. Current policy is largely based on private safety determinations by manufacturers and limited posthoc reassessments after the utilization of DCAs. Therefore, we argue that a revision of the chemical DCA use policy is needed to protect public health.

The goal of this technology assessment is to summarize the existing scientific literature on chemical DCAs while highlighting the gaps in knowledge, and to propose policy options to address the problems associated with DCA use. We will discuss commonly used chemical DCAs and their history, briefly summarize the existing scientific literature, and discuss the unique intersection of the COVID-19 pandemic, civil unrest and DCA regulation. We will end by proposing several policy options that take into account the sparse scientific evidence and remedy the lack of regulation of DCA use.

\section{i. What are DCAs?}

Chemical demonstration control agents (DCAs) are one method used by law enforcement to alter crowd behavior. The intention of these agents is to cause crowd dispersal or to change the crowd's movement trajectory. Chemical DCAs are commonly referred to as tear gas. However, "tear gas" is a blanket term that refers to a number of different chemical agents that cause irritation to the eyes, nose, skin, throat, and lungs, as well as lacrimation (eye-watering). In this paper, we will use both DCA and "tear gas" to refer to this group of chemical agents. The most common tear gas compounds are described below. 
Oleoresin capsicum (OC) is an extract from hot chili peppers of the genus Capsicum, and is the active agent in pepper spray, commonly used by law enforcement. On the Scoville scale, which is used to grade the concentration of capsaicin in peppers and spicy foods, tear gas measures around 500,000-2,000,000 Scoville units, which is 400 times greater than a jalapeno pepper $(5,000$ Scoville units) (Czarnecki 2003). OC has been found to contain over 100 different compounds, including capsaicin, from which the irritating properties of $\mathrm{OC}$ are derived (Olajos and Salem 2001a). OC is a waxy, oily substance, and is combined with an emulsifier like propylene glycol in order to suspend it in water. It is then pressurized to make aerosol pepper spray.

Chloroacetophenone (CN), found in the product Mace ${ }^{\circledR}$, was developed towards the end of World War I and was used both by the military and law enforcement until the 1925 Geneva convention banned its use in war. It continued to be the primary tear gas used domestically by law enforcement up until the 1950s and 60s when CS gas (see below) supplanted it (Olajos and Salem 2001a).

Chlorobenzylidene malononitrile (CS), named "CS" after its creators Corson and Stoughton in 1928, is the most commonly used tear gas today. It is synthesized in a laboratory setting and replaced $\mathrm{CN}$ as the main tear gas used by law enforcement due to its higher dispersal and reported lower toxicity (Tidwell and Wills 2019; Schep, Slaughter, and McBride 2013a).

Dibenzoxazepine (CR) was developed specifically as a DCA in the 1950s. It is more potent and less toxic than CS but also degrades much slower, lingering longer in the environment (Olajos and Salem 2001a; Bessac et al. 2009). Similar to CS, it is also a manmade compound.

The common mechanism among these agents is activation of pain-sensing nerves, known as nociceptive nerve fibers, which typically serve to sense damage and harmful stimuli. Activation of these neurons causes immediate pain and itch, particularly to the eyes, nose, mouth, skin, and respiratory tract (Blain 2003). It is important to note that pain is not the only consequence of activating these neurons. These cells also locally release inflammatory factors and neuropeptides resulting in a snowball effect of inflammation, which can cause damage to surrounding cells (Chaudhry and Rudensky 2013). There are also tissue-specific effects such as mucus secretion in the nose and a coughing reflex in the respiratory tract. Inflammation further exacerbates these responses (Yang and Li 2016).

While these reactions are universal, there is always some individual variability in physiological responses to DCAs. It is suggested that neurogenic inflammation such as that initiated by nociceptors plays a role in the airway inflammation seen in respiratory conditions, including asthma (Kim and Hwang 2013). Additionally, patients with asthma are hyperresponsive to Substance $\mathrm{P}$, one of the major neuropeptides released following nociceptor activation (O'Connor et al. 2004). Thus, some people may be more sensitive to both the acute and longterm effects of tear gas exposure.

\section{ii. Carrier gases and methods of dispersal}

While DCAs are colloquially called tear gases, none of them exist as gases at normal temperatures and pressures. CN, CS, and CR all exist as white crystalline powders at normal temperatures and are dissolved in organic solvents in order to be dispersed into the air (Rothenberg et al. 2016a). These carrier chemicals can be toxic to people, animals, and the environment (Rothenberg et al. 2016b; "Safety Data Sheet Potassium Chlorate, Lab Grade" 2015; "Safety Data Sheet - WEST SYSTEM 105 Epoxy Resin" 2019). The component chemicals of tear gas canisters are often not disclosed. (Lagoe and Eckert 2020). For example, in January 2019, a request for information on the tear gases that Denver police officers use or store was rejected on the belief that it "would be contrary to the public interest," and "could potentially negate [their] effectiveness" (Waters 2019a). Such refusal to disclose can interfere with the ability of doctors to accurately treat patients suffering from the effects of tear gas exposure.

DCAs are discharged with various dispersal methods, including aerosolized sprays, paintball-like rounds and explosive canisters. Different dispersal methods produce different effects based on distance, intensity and environmental conditions such as wind speed and direction. The possibility of harm changes with each variable, making it difficult to accurately test the effects of these devices in a laboratory setting and difficult to assess their safety. (Zekri et al. 1995; 
Krause 2001; Schuhmacher 2020; Mashek 2020; Alhillo et al. 2018).

\section{Historical context for tear gas use}

The 1925 Geneva Protocol has a specific exception for domestic use of chemical weapons. The protocolofficially titled the "Protocol for the Prohibition of the Use in War of Asphyxiating, Poisonous or other Gases, and of Bacteriological Methods of Warfare"prohibits the use of "asphyxiating, poisonous or other gases, and of all analogous liquids, materials or devices" in warfare (Protocol for the Prohibition of the Use in War of Asphyxiating, Poisonous or Other Gases, and of Bacteriological Methods of Warfare (Geneva Protocol) 1925). However, this prohibition does not extend to the use of chemical DCAs within the borders of a sovereign nation against its own citizens. Thus, law enforcement is empowered to use chemical DCAs for riot control. Chemical DCA policy in the United States has little grounding outside of historical pressures and manipulated scientific reports.

Until 1975, the United States made a provision for the deployment of tear gas in war (especially as used in the Vietnam War) but reversed that decision after international pressure ("United States of America: Ratification of 1925 Geneva Protocol" 1975). The Chemical Weapons Convention treaty of 1993 clarified the procedures within the Geneva Protocol. This treaty specifically outlaws the production and use of chemical weapons. However, the it too still allows for the use of Riot Control Agents, which it defines as "any chemical...which can produce rapidly in human sensory irritation or disabling physical effects which disappear within a short time following termination of exposure" ("Customary IHL - Practice Relating to Rule 75 . Riot Control Agents" 1993) (emphasis added). Despite being marketed as temporary, DCAs may have "sensory irritation or disabling effects" which last beyond a short time following their dispersal (Arbak et al. 2014). Therefore, chemical DCAs as currently used might exceed the scope of the exception provided by the Chemical Weapons Convention. Current enforcement of the Chemical Weapons Convention relies on the Organization for the Prohibition of Chemical Weapons, but the Organization has yet to publicly enforce any policy regarding domestic use of chemical DCAs.
The cycle of tear gas usage at protests which sparks international outcry, editorial condemnation and calls for more scientific study has been seen again and again, most recently in the summer of 2020 . Contributing to this cycle is the lack of regulatory oversight and the influence of special interest groups. Chemical DCA manufacturers face little regulatory scrutiny, are privately owned and do not have to report to the public. This is nothing new. Since the beginning of the popularization of tear gas use for law enforcement in the United States, private entities have influenced both national and local policy. Tear gas was initially popularized by United States General Ames Fries after he oversaw its usage in World War I. He saw that this "source of torture" could be employed by law enforcement as a means of "maintaining order and power" (Feigenbaum 2018). Fries himself was endorsed by the Ku Klux Klan and was fond of using "America First" rhetoric in speeches ("Tear Gas - Stuff You Missed in History Class" 2020). General Fries encouraged his fellow veterans to train law enforcement in the use of tear gas leading to the militarization of police. Fries was also involved in creating tear gas production companies, principally the Lake Erie Chemical Company, from which he received monetary kickbacks (Feigenbaum 2020; Jones 1978).

The push to use tear gas domestically was met with considerable public criticism, especially by veterans of World War I who described tear gas as inhumane and hellish (Reid Moir 1922), but General Fries continued to peddle tear gas for domestic use with help from lawyers, scientists and publicists to create compelling propaganda. Tear gas became a go-to tool for undermining acts of civil disobedience due to its psychological demoralizing effect and the physical pain it causes. It has been used throughout history to quell civil rights protests, exactly as General Fries wanted. It is relevant to this discussion to remember that tear gas was engineered as a battlefield weapon in order to kill, rather than incapacitate, enemy soldiers ("Tear Gas - Stuff You Missed in History Class" 2020).

More recently, in February of 1996, former FBI special agent Thomas Ward plead guilty to a felony for accepting unlawful monetary kickbacks from pepper-spray manufacturer Cap-Stun (The New York Times 1996; Habanero 2003). As former chief of pepper-spray testing and research at the FBI, Thomas 
Ward published a widely circulated article and then trained many local law enforcement offices in the use of tear gas, leading to its acceptance in over 3000 departments within a single year. The corrupt and self-serving actions of these two individuals contributed to the current narrative of tear gas being "safe" and to its use by law enforcement.

\section{i. International tear gas use and regulation}

At the international level, no country currently bans the use of chemical DCAs on its own citizens. In 2011, as a result of ongoing protests, the Chilean government temporarily prohibited the use of tear gas citing public concerns about miscarriages (Hayman 2011a). However, scientific studies were inconclusive, mostly due to small sample sizes, and therefore could not conclusively determine whether tear gases are an abortifacient (Guerra 2009). Less than three days later, the Chilean government lifted the prohibition on tear gas after consulting with the private DCA manufacturer even though Chile had previously promised a comprehensive two week health and safety review before this meeting (Hayman 2011b). These reports in Chile are in line with occurrences in 1988, when the United Nations raised concerns about tear gas after the Israeli government used it against Palestinians, resulting in 11 deaths and multiple miscarriages (The Pittsburgh Press 1988).

Governments using tear gas against their own citizens has been occurring for many years, in the face of international and scientific scrutiny, as well as national public outcry. One example is July of 1987, when the government of the Republic of Korea admitted to have used 351,000 canisters and grenades of tear gas during the June Democratic struggle where demonstrations sought to establish a new democratic election system for the thenauthoritarian government ("The Use of Tear Gas in the Republic of Korea: A Report by Health Professionals" 1987; Hiatt 1987). During early protests, university student Lee Han-yeol was critically injured when a tear gas canister penetrated his skull. Lee Han-yeol eventually died from this injury and became one of the major symbols for future protests (Jameson 1987). The tear gas usage continued during the visit of the United States-based organization Physicians for Human Rights in July of the same year. The visiting physicians noted both serious acute illnesses and permanent long-lasting health impacts to possibly millions of South Korean citizens. The Physicians for Human Rights organization concluded that the tear gas use against South Korean civilians was inhumane, yet more research never followed ("The Use of Tear Gas in the Republic of Korea: A Report by Health Professionals" 1987).

Recently, France has banned certain types of chemical DCAs because they contain the explosive compound trinitrotoluene (TNT) and their usage has harmed protestors (Breeden 2020). These tear gas canisters are explosive and have caused shrapnel injuries, including the loss of hands. The French government banned this particular model of tear gas, the GLI-F4, and replaced it with one lacking an explosive compound. However, France has not made any policies regarding the use of tear gas on citizens, which leaves the non-explosive component of tear gas available to possibly harm civilians and the environment.

\section{Current landscape of tear gas use in the United States}

Since the adoption of chemical DCAs by law enforcement departments, the use of DCAs has been criticized as a threat to free speech and public safety (Hu 1989; Williams et al. 2020). Most recently, the killing of George Floyd in Minneapolis, Minnesota by four law enforcement officers on May 25, 2020 sparked local, national and international protests against racial inequality and injustices towards minorities (Taylor 2020). These protests have received considerable media attention, especially with respect to both lawful and unlawful use of chemical DCAs against protestors and declared riots. As law enforcement departments in the United States are controlled by different levels of government (city, township, county, state, federal), each relevant jurisdiction has had to determine whether to use chemical DCAs against protestors. Recently, many cities-Portland, Seattle, Denver, Chicago, New Orleans, Pittsburgh (Allegheny County), Minneapolis, and others - as well as state officials in Oregon, Massachusetts and Michigan have all discussed urgent policy reforms regarding chemical DCAs (Ness 2020). Despite this attention, no state has passed legislation banning the use of chemical DCAs, though some progress is being made in local jurisdictions. 
In June 2020 in the midst of protests, Portland and Seattle both banned the use of chemical DCAs (Riski 2020a; Kamb 2020). The ordinance passed by the City of Seattle proclaims that the city 'supports the right to freedom of speech and freedom of assembly as essential democratic rights' by placing measures against chemical DCA usage (Seattle City Council Record No: CB 118310 2015). In Portland, a temporary restraining order was placed upon the Portland Police Bureau by Chief US District Judge Marco Hernandez to ban chemical DCAs, and the subsequent violations of this restraining order by law enforcement are now being challenged in a lawsuit (Riski 2020a).

In Seattle, while one US District Judge maintained a restraining order on chemical DCA use - citing both improper usage and the present COVID-19 pandemic - the US Department of Justice blocked Seattle's ban, highlighting the hostile legal environment for changes to tear gas policy (Kroman 2020). In both cities, law enforcement was able to circumvent the ban simply by declaring gatherings riots or by using loopholes designed for SWAT teams in order to use chemical DCAs. A lawsuit in New York claims that excessive use of force (which includes improper use of chemical DCAs) was part of a pattern and partly due to a lack of proper police training (Griffith 2021). These cities are an example of the legal battles facing DCA policy reform (Conteras 2020). Considering the over 18,000 police departments in the United States, creating and enforcing chemical DCA law remains a monumental task. We find that policy regarding the usage of chemical DCAs is incredibly limited at all levels of government-international, national, and local-leaving much room for reform.

As described above, private interests have heavily influenced the public acceptance of DCA use as well as DCA regulation and oversight. This influence contributes to the lacking foundational knowledge of these chemicals and their long-term health consequences. A careful review of the available literature indicates that the DCAs currently in use might fall outside of the exception for domestic policing, as their effects do not always "disappear within a short time." Chemical DCAs continue to be used to control crowds through the infliction of pain, and it is imperative to understand the mechanism and possible long-term harm of these weapons.

\section{Regulatory oversight of tear gas}

In the United States, there is no federal oversight of the manufacture of chemical DCAs, unlike compounds such as drugs and pesticides, which are regulated by the Food and Drug Administration and the Environmental Protection Agency, respectively (Carolina 2020). Though some companies may selfregulate to include only FDA-approved or biodegradable ingredients in their products, this is not enforced. After contacting the Environmental Protection Agency, the Centers for Disease Control and Prevention, the Food and Drug Administration, the National Institutes of Health, and the Bureau of Alcohol, Tobacco, Firearms and Explosives, journalists from the Associated Press found that no agency claimed oversight over tear gas (Selsky 2020). Instead, the agencies deflected responsibility between each other, with the EPA referring responsibility to the $\mathrm{CDC}$, and the $\mathrm{CDC}$ citing the EPA as the regulator. Regulation of these products seems to be a metaphorical hot potato: the agency responsible for oversight is either not aware of their responsibility, or there is simply no legislation or enforcement.

Though they do not regulate its production or use, the EPA does set Acute Exposure Guideline Levels (AEGLs) for CS. AEGLs are the air concentrations at which chemicals will have health effects on unprotected civilians (Acute Exposure Guideline Levels for Selected Airborne Chemicals 2014). However, these recommendations are not used for regulatory purposes. Rather, their purpose is to guide emergency planners and protect responders upon release of chemicals into the air. The concentrations are demarcated as: AEGL-1 (notable discomfort and non-disabling irritation), AEGL-2 (long-lasting adverse health effects or impaired ability to escape) and AEGL-3 (life-threatening health effects or death). The EPA states that there is no concentration at which CS can be anything less than AEGL-2, the concentration at which it is "predicted that the general population, including susceptible individuals, could experience irreversible or other serious, longlasting adverse health effects or an impaired ability to escape." It lists the AEGL-2 for CS at $0.083 \mathrm{mg} / \mathrm{m}^{3}$ (Acute Exposure Guideline Levels for Selected Airborne Chemicals 2014)(Table 1). This determination is in direct conflict with most other descriptions of CS, which describe its effects as short lived and nondebilitating. AEGL-3, the life-threatening 
concentration of CS is $140 \mathrm{mg} / \mathrm{m}^{3}$ for a shorter than $10 \mathrm{~min}$ exposure, and just $1.5 \mathrm{mg} / \mathrm{m}^{3}$ if exposed for 4 or more hours.

It is difficult to control the level of CS or any other DCA in the air once deployed, as the air concentration depends on a multitude of factors, including the number of units deployed, the size of the area (i.e., open or enclosed space), and the concentration of the chemical agent in the product. The concentration range of active ingredients in chemical DCA products can vary, and the lack of oversight means that companies can make their own determination about the chemical formulas and intensities included in their products. The EPA has not set AEGLs for OC, CN, CR or any other tear gas.

Without any agency claiming regulatory oversight, it is difficult for civilians, doctors, or scientists to know the chemical composition of DCAs and their carrier gasses. DCAs are banned in war per the 1925 Geneva Protocol and 1997 Chemical Weapons Convention, and yet there is no regulatory body responsible for overseeing the manufacturing of DCAs or their use on U.S. citizens. We will now briefly review the scientific literature available on the effects of chemical DCAs on human health and the environment.

\section{Review of health and environmental effects of DCAs}

\section{i. Animal studies on chemical toxicity}

Chemical safety testing of DCA's has historically relied heavily on animal models to assess the hazards that manufactured chemicals may have on human health and the environment. While these studies can yield powerful insights into the toxicity of new compounds, they are limited in that they cannot fully recapitulate either the biological or environmental contexts of human exposure. Overall, animal research has demonstrated that at best DCA's are potent peripheral sensory irritants that can cause adverse respiratory and sensory reactions in those exposed and, at worse can be lethal at the highest doses and longest exposure times. However, these studies cause an immense amount of pain, discomfort, and death in experimental animals. Animals are exposed to extraordinarily high concentrations of DCA's in order to determine the toxic effects and therapeutic window (the dose at which tear gas causes discomfort but not death) of various DCA's.
Additionally, the various aerosolization methods of DCA's are not necessarily studied despite the potentially toxic compounds that are released via pyrotechnic (thermal and smoke based aerosolization) versus pure compound aerosolization, which leaves an astounding lack of understanding of the severity of health effects that may occur from DCA exposure.

There is an overall dearth of basic research evaluating the toxic effects of tear gas compounds following the 1990's, despite evolving components of DCA chemicals and dispersal techniques. This lack of continued basic research is in part due to the creation of the Institutional Animal Care and Use Committee (IACUC) in 1986, which is responsible for the oversight of animal care in research ("The Institutional Animal Care and Use Committee" 2015). To inflict pain on animals in research, a scientist must have a justifiable reason that will be of benefit to human health or well-being (i.e., studying and identifying pain receptors that lead to the development of medicine to alleviate chronic pain in humans). The lack of continued basic research on chemical DCA's and aerosolization methods can likely be attributed to the stringency of the IACUC guidelines and the lack of a justifiable human benefit that would come from exposing animals to the painful effects of chemical DCA's.

Therefore, new research on the toxicity of chemical DCA's cannot be ethically conducted on vertebrate animals, as it would not lead to a justifiable benefit to human health or any mechanistic insight into disease. In this context, the usage of these compounds on humans should cease entirely. This is especially true because the scientific community cannot accurately gauge the health risk of acute, prolonged, and repeated exposure to tear gas and therefore these compounds carry a high and unnecessary amount of risk to our population.

ii. Health effects of DCAs in human studies and incidental exposures

In humans, the acute effects of DCA exposure are similar to the effects documented in animal studieseye redness, runny nose, cough, shortness of breath, phlegm, and chest pain (Karagama, Newton, and Newbegin 2003; Arbak et al. 2014; Kearney et al. 2014; Ilgaz et al. 2019). However, few studies systematically and rigorously analyze their long-term 
health impacts. Furthermore, while physical health is the primary focus of most studies, mental health can also be impacted. Few studies have been conducted on the psychological effects of DCAs, but posttraumatic stress, anxiety, and panic can all be persistent psychological responses to exposure (Nathan et al. 2003; Alhillo et al. 2018; Haar, Iacopino, Ranadive, Weiser, et al. 2017). Drawing conclusions from the small pool of published studies that do analyze long-term effects is challenging due to the widely varied methods of DCA exposure and the largely non-representative subject pool used in the testing.

Many studies utilized people who had been incidentally exposed to DCAs, such as while attending a protest, and relied on individual recollections of health events. Still, the studies indicate that respiratory problems often occur in the days or weeks after DCA exposure and have the potential to linger for 10 months or longer (Arbak et al. 2014; Dagli et al. 2014; Karagama, Newton, and Newbegin 2003). These persistent symptoms included worsening of asthma, decreased exercise tolerance, and coughing. Interestingly, chest pain was more often listed as a symptom more than 24 hours after DCA exposure, rather than immediately after exposure, in multiple studies (Wheeler et al. 1998; Ilgaz et al. 2019). This delay in symptom onset could confound studies that only assess acute responses or rely on self-reporting, and lead to an underestimation of the health impacts. The wide range of DCA exposure durations, instances, intensities, weather conditions, and deployment methods in human studies further complicates extrapolation from their findings. These variables make comparison between reports on DCA safety difficult (Arbak et al. 2014; Karagama, Newton, and Newbegin 2003; Dimitroglou, Rachiotis, and Hadjichristodoulou 2015).

Some of the most well-controlled DCA studies come from the U.S. Army, where recruits are exposed to CS during basic training to ensure they are competent in the use of respirator masks (Hout et al. 2014). A mixed-sex cohort of 6,723 trainees was exposed to similar amounts of CS gas, and their likelihood of reporting acute respiratory illness following exposure increased by $244 \%$ compared to the week prior to exposure. Nonetheless, crucial information such as the recruits' sex, smoking status, age, and the length of CS gas exposure were not provided by the study. While army recruits might be a more homogenous group in terms of age and physical fitness, with the majority being early-20s white males ("Military Recruitment 2010" 2011), most crowds exposed to DCAs have a more variable composition of individuals.

Sex, smoking status, pre-existing health concerns, and age are all important characteristics that might influence a person's likelihood of developing longterm health complications or even death in response to DCA exposure (Arbak et al. 2014; Kearney et al. 2014). While relatively rare, deaths have occurred due to DCA exposure. Those deaths usually occurred directly or in conjunction with pre-existing asthma, which was triggered or exacerbated by the exposure, or by triggering a stroke or heart attack (Toprak et al. 2015; New York Times 1995; Zakhama et al. 2016; Olajos and Salem 2001b; Çil et al. 2012). Despite the importance of accounting for diverse populations, most of the available studies were done on generally healthy males, neglecting other groups. Consequently, the level of DCA exposure required to elicit symptoms, toxic effects, and lethal outcomes has not been well established, especially among diverse populations (Haar, Iacopino, Ranadive, Weiser, et al. 2017).

There are conflicting opinions about the safety of DCAs due to conflicting evidence about the long-term effects of DCA exposure (Karagama, Newton, and Newbegin 2003; Schep, Slaughter, and McBride 2013b; Arbak et al. 2014). Despite these differences, many experts agree that new data are needed that rigorously test the long-term effects of newer DCAs on a variety of human populations (Rothenberg et al. 2016b; Arbak et al. 2014; Ilgaz et al. 2019; Unuvar et al. 2013; Olajos and Salem 2001a; Dimitroglou, Rachiotis, and Hadjichristodoulou 2015; Zakhama et al. 2016). Despite these persistent calls, few new studies have been conducted, and these substances continue to be used (Lai, Marsh, and Singhvi 2020). Only with more complete data can tear gas conclusively be called "safe" and "less-lethal" (Ilgaz et al. 2019). However, the data currently available indicate the persistence of more severe and longlasting health impacts than are currently widely acknowledged. With animal studies unlikely to provide a direct benefit for human health, it is hard to 
justify purposefully exposing human subjects to these substances for research purposes.

Despite the paucity of basic research evaluating longterm health effects following sub-lethal chemical DCA exposure, we are not advocating for further studies that purposefully expose study participants to these chemicals. Instead, health and research professionals should invest in monitoring the health status of individuals that have been incidentally exposed either acutely or repeatedly to chemical DCA's. This observational post-hoc analysis would allow realistic assessments of the immediate and prolonged health effects that occur following chemical DCA exposure without necessitating inhumane research on humans or animals (Kaske et al. 2021). Chemical DCA's were created to immediately disable opponents in war, they serve no benefit to human health and wellbeing and therefore cannot justifiably be studied.

\section{iii. Environmental effects of DCAs}

As in the case of human health, the effects of tear gas on the environment are understudied and concerning ("Safety Data Sheet - CS Pellets" 2013; "Safety Data Sheet - First Defense Stream OC Aerosol" 2018). Several key properties of DCAs make them particularly alarming from an environmental perspective, including their uncontrollable spread, their potential to accumulate in soil and water, and their toxicity to plant and animal life.

Once deployed, DCAs cannot be controlled and often spread to affect unintended areas and people. Recent reports exist of gases invading nearby homes and forcing people to evacuate (Riski 2020b). CS has been found in snow up to 30 days following deployment and 70 meters (230 feet) away from the grenade detonation (Johnsen et al. 1985).

Research on the effects of DCAs as soil and water pollutants is sparse. However, the known literature on the subject suggests that DCAs are harmful to plants and animals and may persist in the environment for a long period of time. Both CS and its principal decomposition components have toxic effects on flora, causing leaf damage and reduced growth (Morrison, Dralle, and Demaree 1974; Worthley 1971). Malononitrile, a product of CS degradation, is classified as being as toxic as cyanide (Keller, Elves, and Bonnin 1986). CS is highly soluble in water, meaning that it can easily leech into bodies of water near the deployment area. Even at relatively low concentrations in water, toxicity to fish species has been reported (Keller, Elves, and Bonnin 1986). According to European Union regulations, CS pellets are classified as "harmful to aquatic life with longlasting effects", and "may cause adverse effects in the aquatic environment" "Safety Data Sheet - CS Pellets" 2013). Though not thoroughly studied, the available evidence suggests that CS has detrimental and longlasting effects, especially to aquatic habitats.

Efforts to mitigate any potential harm to the environment by DCAs are made difficult both by the lack of research on these compounds and reluctance on the part of police departments to release information on the products they use. Safety Data Sheets (SDS) contain information about the potential and known hazards that chemicals pose, as well as information on responsible handling, disposal, and treatment. Frequent blank entries in the SDSs of common DCAs highlight the scarcity of information on the effects of these chemicals on human and environmental health. For example, Defense Technology Oleoresin Capsicum Solution 0.2\%, which is used by the Minneapolis Police Department, is described on its safety data sheet as having "no relevant information available" for the following fields: subacute to chronic toxicity, repeated dose toxicity, aquatic toxicity, persistence and degradability, bioaccumulative potential, and mobility in soil.

Furthermore, the identities of the specific compounds used by law enforcement are often purposefully concealed from the public because it is tactically advantageous for police departments to obfuscate this information (Waters 2019b; Lagoe and Eckert 2020). Such refusals amplify the difficulty of monitoring or ameliorating the accumulation of potentially harmful chemicals in the environment.

In sum, few experiments have been conducted to test the effects of DCAs on the environment and there are significant concerns about their accumulation in soil and water. Environmental exposure mitigation efforts and cleanup efforts are made more difficult by police departments' refusals to release information on the specific compounds they use on the public. Even if environmental accumulation of these chemicals proves to not have a direct effect on humans, the potential long-lasting effects on aquatic 
life and local flora themselves warrant cessation of their use at least until full investigations can be completed. Based on the available scientific evidence, and lack thereof, we propose several alternative policies for the regulation and oversight of DCA use to better protect the environment and human lives.

\section{Policy options}

\section{i. Implement de-escalation procedures to decrease DCA deployment}

Modification of deployment protocols to increase communication is one policy option to decrease DCA misuse and minimize injury. Tear gas not only presents several health hazards, but it is a technology that is frequently misused by police and used in an abundance of situations that would not be recognized as riots (Temple-Raston 2020). Prior to using tear gas as crowd control, police should be mandated to use de-escalation methods, reserving tear gas as a last resort when other verified methods of non-lethal crowd de-escalation and dispersal techniques have been tried. De-escalation includes "tactics and techniques used by officers, when safe and feasible without compromising law enforcement priorities, that seek to minimize the likelihood of the need to use force during an incident and increase the likelihood of voluntary compliance" (Diaz 2020a). While this seems straightforward, recent events have shown that a clear and precise protocol needs to be developed that can be easily adopted by different municipalities to aid in understanding how and when to use crowd de-escalation techniques vs. chemical DCA's. The adoption of such a protocol would minimize the likelihood of violence and promote thoughtful resolution to community/police conflicts.

The newly adopted Seattle PD De-Escalation Policy (Diaz 2020b), combined with the Madison Method (Marcou 2011), can be used as a template for other police departments around the country. The Seattle PD de-escalation protocol lays out four de-escalation tactics to be adopted during unrest including: communication, time, distance and shielding. We suggest adding aspects of the Madison Method to this, including a recognition from officers that it is their job to facilitate and protect the public's right to freely speak and assemble, to protect people first and property second, and to engage with protest participants before, during and after demonstrations (Marcou 2011). The following section will include a summary of these tactics to inform future protocol development.

First, communication should be used before, during, and after protests. Police should engage with organizers and participants of protests, when possible, to determine the protest gathering route and purpose. By engaging with the community in this way the police can act as facilitators and protectors of the First Amendment and not opposition actors. Additionally, building this relationship beforehand can be useful when attempting to gain voluntary compliance for crowd dispersal in the event protests turn to riots. Use of voluntary compliance for crowd dispersal includes verbal persuasion (not including threats of force) and clear instructions for dispersal. Communication also involves thoughtful consideration of why non-compliance or resistance is occurring such as: the immediate environment, medical conditions, mental impairment, physical limitation or language barriers. One amendment that should be added to this section of the protocol is to utilize community leaders in communication with crowds. Placing community "consultants" on police task forces who can engage with crowds before and during protests in a less threatening and more equitable manner than police, may help facilitate more expedient crowd dispersal when necessary.

When crowd dispersal becomes necessary, officers need to supply time to protestors for evacuating premises. Providing a clear and allotted amount of time before police escalation to dispersal tactics may help stabilize situations more effectively, giving officers more options for resolving the incidents. During this allotted time police may call for extra resources, such as designated social workers who are trained in non-lethal techniques of de-escalation and who can better identify people that are under the influence of drugs or who may have mental impairments. Additionally, social workers are more accustomed to working as partners within the communities they serve.

Third, distance and shielding are recommended. Distance involves maximizing tactical advantage by increasing distance between police and demonstrators to allow for greater reaction time. Distance can also decrease the threat perceived by the crowd from police and thus may decrease the amount of turmoil and violence that results. Shielding 
involves placing barriers between uncooperative subjects and officers and using natural barriers in the environment (such as buildings). While shielding is a useful strategy to protect officers it can also lead to roadblocks, cutting off points of access or escape for crowds. This can be especially detrimental if tear gas is eventually used, as clear escape routes need to be available (Kirby 2020).

Lastly, an effective protocol will need to include ways to remove violent members of a demonstration without threatening the right of the group to assemble and protest. This could include targeted arrests of individuals observed by at least two officers committing a crime (e.g., breaking and entering, arson, assault). Additionally, if tear gas becomes an absolute necessity to disperse a crowd, there should be a trained individual who works in tandem with a community leader to make the call of when to use "less-lethal" force in a controlled and safe way, without excess. Police also need to be held accountable for not only following a de-escalation protocol prior to "less-lethal" force, but also for notifying the public prior to tear gas use, for ensuring that protesters have a safe means of escape from tear gas exposure, for not using tear gas in excess and for rendering medical aid after dispersal ("5-300 Use of Force - City of Minneapolis" 2020a).

While the creation of a protocol can be an effective first step in ensuring that DCAs are used appropriately, it cannot completely rectify DCA misuse by police. It must be considered that some police forces may refuse to adopt a general protocol or will be difficult to be held accountable for following the protocol properly. We too often see police actions cause an escalation of peaceful protests into violent riots (Buford et al. 2020). The adoption of a deescalation protocol that protects the First Amendment right to gather and protest, could be an essential step to protecting communities and police forces, and in reducing the community and environmental impact of incorrect tear gas use. To further ensure the effectiveness of the recommended protocols, enforcement and transparency will also be needed.

\section{ii. Create enforcement protocols for the responsible use of DCAs}

Increasing the enforcement of pre-existing protocols and creating additional oversight would promote police accountability while decreasing DCA misuse. Many of the preventable issues caused by DCA use are rooted in breaches of police protocol, or misuse of the agents themselves. For example, Minneapolis Police Department policy dictates that officers "shall exercise due care to ensure that only intended persons are exposed to the chemical agents", and that officers should administer post-exposure treatment to those exposed to the agent, including either removing the person from the affected area or rinsing their eyes and skin with cool water ("5-300 Use of Force - City of Minneapolis" 2020b). As we have described, DCAs affect individuals indiscriminately due to their gas-like nature, making it nearly impossible to ensure that only the intended targets are affected by the chemicals. It is apparent that little to none of this assistance is given to exposed individuals by police officers despite the existence of aid directives. There are even accounts of police officers directly impeding medics from delivering aid (Lunsford 2020). Additionally, manufacturers of DCA canisters warn that the canisters should not be aimed directly at individuals because of the potential for serious bodily harm ("3233 - 37MM CS Multi 3, Pyro, 4.9" Long - Combined Systems" n.d.; Smith 2011), yet police officers do not always take this precaution (Mashek 2020; Rivas 2020).

Protocols and procedures for tear gas use and its aftermath, such as the one described above or ones that are pre-existing, must be enforced in a manner that ensures compliance and accountability by law enforcement. These protocols could be enforced by oversight committees, similar to those already in place for the discharge of a firearm. An accessible complaint submission and review process must also be implemented- one that allows the public to report instances of misuse and receive updates about the status of a complaint. This is similar to a ballot measure that recently passed in Berkeley California, establishing a new police oversight board with civilian members ("Berkeley, California, Measure II, Police Accountability Charter Amendment (November 2020)" 2020). Such review boards could increase community involvement in police policy, increase the accountability of departments to their communities and build trust.

Formal complaints against police officers' use of force often result in inaction. A recent federal report of almost 1000 police departments in 2015 reported an 
average of $7 \%$ of complaints being sustained, indicating that few cases present sufficient evidence to warrant disciplinary action against an officer (Jacoby 2019). Although the U.S. Attorney General's Office is required to collect data on police use of force under the Violent Crime Control and Law Enforcement Act Section 210402 ([D-TX-9] 1994), there is no federal oversight and therefore little structure for how such complaints are recorded. The process of submitting complaints against officers for inappropriate use of force is often confusing, inaccessible, and ineffective (Sawyer and Jany 2020). The process of filing and the outcome of each complaint should be made more easily available to the public, increasing the accountability of the police department and individual law enforcement agents.

Even with increased oversight of the use of DCAs and increased transparency into the complaint and oversight process, punitive actions against offending officers is not a guarantee. Eliminating or heavily altering qualified immunity is a complex issue that is beyond the scope of this paper but is one option for ensuring better accountability for harmful actions. Qualified immunity is a doctrine that protects government officials from monetary suits when violating constitutional rights, as long as their actions did not "violate clearly established statutory or constitutional rights of which a reasonable person would have known" (Sobel 2020; Harlow v. Fitzgerald 1982). When applied to police officers who are being sued for an excessive use of force, lower courts often dismiss lawsuits due to a lack of legal precedent from significantly similar examples of police brutality, or "clearly established" precedent (Totenberg 2020; Chung et al. 2020). Holding police officers accountable for the misuse of DCAs or mistreatment of the public following their deployment would therefore only be effective and lead to punitive action if qualified immunity doctrines were revised.

Police officers, unions and associated lobbying groups may see these new policies and accountability measures as hindering their ability to use non-lethal force and would likely resist such changes. However, increasing accountability for the misuse of DCAs against citizens would help to deter police and commanding officers from using excessive force, or from using DCAs incorrectly. Although altering the qualified immunity doctrine would take time, legal battles and a significant investment in administrative overhaul, it would increase accessibility and transparency in the complaint process and further ensure compliance with existing procedures. Ensuring that police protocols emphasize the need to provide aid to individuals affected by DCA deployment and increasing the enforcement of these protocols may increase the public's trust in police officers and reduce the potential for harm on all sides.

While issues of race in policing are not the main focus of this article, it is within our scope to consider disparities in the use of chemical DCAs. A new study of police treatment of protestors found that leftleaning protestors were more likely to be arrested than right-leaning protestors. Even when accounting for the number of protests held, left-wing protestors were arrested more than twice as much as right-wing protestors (Wood 2020). This article was published after the Black Lives Matter protests swept the country, but before insurrectionists stormed the U.S. Capitol. The difference in police response-where peaceful protestors can be gassed to clear the way for a photo op, but insurrectionists destroying the seat of our democracy largely were not-can be easily compared (Beckett 2021). Police culture and bias impact how police targets are treated and both race and political affiliation contribute to un-equal and inappropriate use of force. It is therefore important to acknowledge that chemical DCAs were originally sold with the subtle message that they were useful in quelling the voices of people of color. Creating review boards made of community members to review police policy and discipline is one possible way to help address these issues.

iii. Ban chemical DCAs during the current COVID-19 and future respiratory pandemics

A temporary ban on DCA deployment during current and future respiratory pandemics could help prevent the spread of disease. Phlegm, coughing, shortness of breath, and other respiratory issues are all possible health concerns after exposure to DCAs. While this is concerning enough on its own, it cannot be overlooked that at the time of this article, the world is in the grip of the COVID-19 pandemic and social justice movements are incredibly active. The Centers for Disease Control lists cough and difficulty breathing as symptoms of COVID-19 (CDC Centers for Disease Control 2019). For many patients, the assistance of a ventilator is needed (Richardson et al. 
2020) and even then, many still die due to respiratory failure (Ruan et al. 2020). Using DCAs can contribute to ventilator shortages by using resources needed by COVID patients (Ranney, Griffeth, and Jha 2020). In one report, 8 out of 23 young people exposed indirectly to DCAs needed oxygen therapy (Breakell and Bodiwala 1998), and the availability of oxygen and ventilators has been scarce during parts of the COVID-19 pandemic (Ranney, Griffeth, and Jha 2020). While the use of DCAs should receive more scrutiny even without the COVID-19-related concerns, it seems particularly perilous to continue to use crowd control measures that cause respiratory impairments in the middle of a respiratory pandemic.

When DCAs are used on crowds, sometimes peacefully protesting, ("ACLU, GROUPS SUE TRUMP FOR FIRING TEAR GAS AT PROTESTERS OUTSIDE THE WHITE HOUSE" 2020) it is impossible to know who among them might be at high risk for COVID-19 or have underlying health conditions. Firing gas into a crowd causes fits of coughing, which can spread COVID-19 (Song 2020; Baker 2020). This is not just a risk taken by the crowd being fired upon, but by law enforcement in the area as well as any first responders and reporters. Coughing in a heterogenous crowd increases the risk of COVID-19 exposure to everyone in the vicinity.

Proponents of DCA use call it a "non-lethal" method (Fowers, Steckelberg, and Berkowitz 2020). While that is usually true, it is certainly not always the case, as deaths from DCAs have been reported (Ashcroft, Daniels, and Hart 2003; Toprak et al. 2015; Alhillo et al. 2018) and the use of DCAs during a pandemic could turn them into lethal weapons by increasing an individual's risk for contracting a virus for which there is currently no cure (CDC 2020).

At this time, when longitudinal studies on DCAs are lacking and the world struggles with a respiratory pandemic, a temporary ban on the use of DCAs would protect public health. Studies indicate decreased respiratory function can linger for months after DCA exposure (Arbak et al. 2014) which could make people more susceptible to COVID-19, especially when coughing in crowds (Baker 2020). Hospitalization for DCA exposure might involve the use of ventilators which are needed to treat COVID patients (Richardson et al. 2020). Since the national shortage of ventilators has led to universities and companies scrambling for alternatives to provide for hospitals (Glynn 2020; Ranney, Griffeth, and Jha 2020), preventing hospitalizations due to tear gas use is logical. If banned during the pandemic, law enforcement officials would be able to use methods of controlling protests that have less risk of spreading COVID-19. Once a successful vaccine is available, and herd immunity established, the ban could be lifted (Mayo Clinic 2020). This policy option addresses the combined problem of COVID-19 and chemical exposure and would reduce the number of patients potentially needing ventilators but does not address the dangerous and unknown long-term effects of DCA exposure. This option is more protective of public health during the pandemic, but that protection would subside along with the emergency and does not address the underlying issues. While a step to protect public health, it is only a small and temporary one, and longer-term policy solutions are needed.

\section{iv. Ban DCA use permanently}

A permanent ban on DCA use would be the most stringent policy option and the most protective of human health. There are both known and unknown health risks associated with DCA use (Dimitroglou, Rachiotis, and Hadjichristodoulou 2015), making it difficult to craft informed policy. The risk to protestors and bystanders is increased by the continued incorrect use of DCAs despite training and manufacturer instructions. Disallowing the use of DCAs would remove the health and safety risks associated with their deployment. Police rely on DCAs to control large crowds at longer distances, and to reduce the risk to officers. Closer proximity of law enforcement and demonstrators could increase the likelihood of physical violence. However, physical barriers can also be used to control crowds and increasing the proximity of law enforcement to protests could encourage the use of de-escalation techniques rather than force. Greater proximity could also allow police to target specific bad actors, rather than an entire crowd. Banning DCAs could save money since police departments wouldn't need to purchase canisters or associated equipment like gas masks. It could also save money by eliminating the threat of lawsuits and investigations, like the many in progress around the country, against cities and police departments (Blumberg 2020; "DOJ OIG Announces Initiation of Work" 2020; Goyette v. City of Minneapolis 2020). 
A ban on DCA use would remove the threat of unknown and potentially long-term health risks and prevent any chilling effects on free speech. For example, a person with asthma or another underlying health condition might be hesitant to attend a peaceful protest out of fear that they might be exposed to tear gas and have a health emergency. The fear of being able to safely exercise their right to protest could prevent such individuals from attending, and thus impair their constitutional rights (U.S. Const. amend. I.).

Police departments might have to compensate for the loss of DCAs as a response option by purchasing other equipment, so it is not clear what the net saved cost would be. Additionally, a complete ban is likely to be unpopular amongst police and their supporting organizations. While it does not leave police without resources (kinetic projectiles, physical force, sound, etc.), the loss of DCAs as a response option would undoubtedly change the way law enforcement can respond to some situations. The decentralized governmental framework of the U.S. means that individual states or cities could decide whether or not to completely ban chemical DCAs. Currently, the majority of policing policy is determined internally by the police department or the local government oversight body. With the limited number of rigorous animal, human, and environmental studies available, banning chemical DCA use locally, at the state level, or nationally is the policy option that is most protective of public health.

\section{v. Alternatives to chemical DCAs also pose risks}

Alternative demonstration control technologies can also threaten human health or are insufficiently regulated and studied. Therefore, they should not be considered as alternatives to DCA use, and we would not recommend using them as substitutes for chemical DCAs. Some examples of these alternative methods are long-range acoustic devices (LRADs), active denial systems, and kinetic projectiles, all of which are currently in use to different extents. Once promoted as non-lethal, deaths by deployment of these alternative crowd control methods can occur. Advocates of these alternatives cite that they are "less-harmful" crowd control options, but there is little evidence to suggest that these alternatives are safe and can be used discriminately to protect public health and free speech. Therefore, we present the following alternatives to show the risks inherent in less-lethal crowd control and we instead advocate for policy changes regarding deployment, regulation, and enforcement protocols.

Active denial systems, commonly referred to as "heat ray devices", are another relatively new alternative to DCAs to help control crowds. The active denial device forms a high-powered beam of directed, millimeter wavelength energy to cause a heating sensation to superficial layers of skin, heating the skin to around $111^{\circ} \mathrm{F}\left(44^{\circ} \mathrm{C}\right)$ (Kenny et al. 2008). While this is lower than the temperature needed to cause first degree burns, it causes an intense burning sensation that almost immediately subsides when the beam is removed (Ackerman 2012). Rare instances of seconddegree burns have been reported from the active denial system ("Active Denial System FAQs," n.d.), but more research that emulates real-world use situations may be necessary to ensure its safety. While this technology is effective at deterring individuals from remaining inside the beam, like the LRAD siren, it gives no visual warning or demarcation of where the beam is directed. In a situation where a crowd of individuals who have no experience with this device are targeted, it may cause panic. While this device, if adequately tested, could be an alternative to chemical weapons in the future, its cost might remain a barrier to widespread adoption (Hambling 2009).

Kinetic projectiles such as rubber bullets and bean bag rounds are more transparent in the dangers they pose-physical deterrence and harm. They are often used incorrectly according to police protocol, are difficult to aim, and often result in permanent physical damage to victims, with a reported $3 \%$ of direct impact instances causing death (Haar, Iacopino, Ranadive, Dandu, et al. 2017). Similarly, misuse of tear gas deployment technologies has led to direct impact from tear gas canisters, resulting in permanent injury to protestors and press. Multiple instances of physical harm during 2020 protests in Paris, France resulted in the ban of explosion-based tear gas canisters, but not tear gas itself (Breeden 2020).

While other "less-lethal" options do exist for crowd control purposes, all of the options also have significant safety concerns. A recent post-hoc study of injuries from "less lethal" weapons used for crowd control in Minneapolis echoed previous findings about the dangers posed by commonly used tear gas 
alternatives (Kaske et al. 2021). Despite these drawbacks, however, the more obvious and known dangers of some of the "less lethal" alternatives (such as direct physical injury) may render them more favorable than DCA use, which poses dangers that are not fully understood. Law enforcement agencies must carefully consider the risks to human health and safety posed by alternative crowd control technologies and should review any protocols for their use.

\section{Conclusion}

Despite numerous calls for more research on the unknown and potentially deadly effects of chemical DCAs (New York Times 1995) little progress has been made in the last 30 years. Without conclusive evidence of their safety, continuing to use these chemicals on crowds amounts to testing unknown compounds on the public. Although limited studies have been conducted, research clearly shows that both the active ingredients in DCAs and their carrier gases are harmful to humans and animals. The animal studies on which many of the human exposure guidelines are based were conducted to determine lethal doses of DCAs and thus offer little insight into the various health impacts of acute exposure. There are very few human studies assessing long-term health consequences of DCA exposure and those that exist are highly constrained. This lack of rigor endangers the public due to poorly informed safety and use guidelines. Additionally, a stark lack of

\section{References}

[D-TX-9], Representative Jack Brooks. 1994. H. R. 3355 Violent Crime Control and Law Enforcement Act of 1994. 103rd Congress.

https://www.gpo.gov/fdsys/pkg/BILLS103hr3355enr/pdf/BILLS103hr3355enr.pdf\%0Ahttp://www.copyright.go v/legislation/s505.pdf.

“3233 - 37MM CS Multi 3, Pyro, 4.9" Long - Combined Systems." n.d. Combined Systems. Accessed March 10, 2020.

https://www.combinedsystems.com/product/32 33-37mm-cs-multi-3-pyro-4-8-long/.

“5-300 Use of Force - City of Minneapolis.” 2020a. MinneapolisMN.Gov. 2020. www.minneapolismn.gov/police/policy/mpdpoli cy 5-300 5-300.

“5-300 Use of Force - City of Minneapolis.” 2020b. MinneapolisMN.Gov. 2020. information regarding the effect of DCA's on the environment means it is especially difficult to test for contaminants as the components of DCAs are rarely disclosed and there is little research on the breakdown products or how to neutralize them.

With the confluence of a respiratory pandemic, widespread protests, and deployment of DCAs, we are at a point at which current tear gas policy is insufficient. There is presently no oversight for the manufacture of these compounds, and rampant reports of police misuse of these weapons indicates that the existing policies are severely lacking. Here, we proposed policy changes to address some of the problems with tear gas use and misuse. Increased regulatory oversight would allow for identification of the exact compounds used in DCAs and their respective dangers. Adopting de-escalation protocols could reduce the use of DCAs and enforcement of proper use of these weapons would decrease the risks to all police, demonstrators, and bystanders. Implementation of community review boards could increase police accountability and foster community engagement. Lastly, banning tear gas use while the nation is gripped by a respiratory pandemic could help slow the spread of COVID-19 and allow citizens to exercise their right to protest. Chemicals originally designed to kill or maim and that have been banned from use in war, especially under-studied, underregulated ones, should not be used with impunity on the public.

Ackerman, Spencer. 2012. "Video: I Got Blasted by the Pentagon's Pain Ray - Twice.” Wired, March 12, 2012. https://www.wired.com/2012/03/painray-shot/.

"ACLU, GROUPS SUE TRUMP FOR FIRING TEAR GAS AT PROTESTERS OUTSIDE THE WHITE HOUSE." 2020. 2020. https://www.aclu.org/pressreleases/aclu-groups-sue-trump-firing-tear-gasprotesters-outside-white-house.

"Active Denial System FAQs." n.d. Joint Intermediate Force Capabilities Office. https://jnlwp.defense.gov/About/FrequentlyAsked-Questions/Active-Denial-System-FAQs/.

Acute Exposure Guideline Levels for Selected Airborne Chemicals. 2014. Acute Exposure Guideline Levels for Selected Airborne Chemicals. National Academies Press. https://doi.org/10.17226/18707. 
Alhillo, Haider T., Mohamed M. Arnaout, Hayder S. Radhi, Mohammed A. Al-Dhahir, Luis R. Moscote-Salazar, and Samer S. Hoz. 2018. "Direct Head Injury Caused by a Tear Gas Cartridge. Questions on Safety: A Case Report from Iraq and Review of the Literature." Journal of Clinical Neuroscience 56: 179-82. https://doi.org/10.1016/i.jocn.2018.06.051.

Arbak, Peri, Ilknur Başer, Özlem Ozdemir Kumbasar, Füsun Ülger, Zeki Kiliçaslan, and Fatma Evyapan. 2014. "Long Term Effects of Tear Gases on Respiratory System: Analysis of 93 Cases." Scientific World Journal 2014: 5-9. https://doi.org/10.1155/2014/963638.

Ashcroft, John, Deborah J. Daniels, and Sarah V. Hart. 2003. "The Effectiveness And Safety of Pepper Spray." NCJ, no. 195739.

Baker, Mike. 2020. "Corrosive Effects of Tear Gas Could Intensify Coronavirus Pandemic." The New York Times, June 3, 2020. https://nyti.ms/2XZpOAx.

Beckett, Lois. 2021. "US Police Three Times as Likely to Use Force against Leftwing Protesters, Data Finds," no. April 2020: 1-5.

"Berkeley, California, Measure II, Police Accountability Charter Amendment (November 2020)." 2020. Berkeley, California. https://ballotpedia.org/Berkeley,_California,_Me asure_II,_Police_Accountability_Charter_Amendm ent_(November_2020).

Bessac, Bret F., Michael Sivula, Christian A. Hehn, Ana I. Caceres, Jasmine Escalera, and Sven-Eric Jordt. 2009. "Transient Receptor Potential Ankyrin 1 Antagonists Block the Noxious Effects of Toxic Industrial Isocyanates and Tear Gases." The FASEB Journal 23 (4): 1102-14. https://doi.org/10.1096/fj.08-117812.

Blain, Peter G. 2003. “Tear Gases and Irritant Incapacitants: 1-Chloroacetophene, 2Chlorobenzylidene Malononitrile and Dibenz[B,F]-1,4-Oxazepine." Toxicological Reviews. Toxicol Rev. https://doi.org/10.2165/00139709-20032202000005 .

Blumberg, Peter. 2020. "Black Lives Matter, ACLU Sue Trump Over Tear Gassing Protesters." Bloomberg, June 4, 2020. https://www.bloomberg.com/news/articles/202 0-06-04/black-lives-matter-aclu-sue-trump-overtear-gassing-protesters.

Breakell, A., and G. G. Bodiwala. 1998. "CS Gas Exposure in a Crowded Night Club: The Consequences for an Accident and Emergency Department." Emergency Medicine Journal 15 (1): 56-57. https://doi.org/10.1136/emj.15.1.56.
Breeden, Aurelien. 2020. "France to Stop Using TNTLoaded Tear Gas Grenades." The New York Times, January 27, 2020. https://nyti.ms/30W84H4.

Buford, Talia, Lucas Waldron, Moiz Syed, and Al Shaw. 2020. "We Reviewed Police Tactics Seen in Nearly 400 Protest Videos. Here's What We Found." ProPublica, July 16, 2020. https://projects.propublica.org/protest-policetactics/.

Carolina, North. 2020. "Lack of Study and Oversight Raises Concerns about Tear Gas." https://apnews.com/c814cc7b873ccaf60b95b10 e96ecfc12.

CDC. 2020. "Information for Clinicians on Investigational Therapeutics for Patients with COVID-19." Centers for Disease Control and Prevention. 2020. https://www.cdc.gov/coronavirus/2019ncov/hcp/therapeutic-options.html.

CDC Centers for Disease Control. 2019. "Symptoms of Coronavirus | CDC." Centers For Disease Control and Prevention, 2019-21.

https://www.cdc.gov/coronavirus/2019ncov/symptoms-testing/symptoms.html.

Chaudhry, Ashutosh, and Alexander Y. Rudensky. 2013. "Control of Inflammation by Integration of Environmental Cues by Regulatory T Cells." Journal of Clinical Investigation 123 (3): 939-44. https://doi.org/10.1172//CI57175.

Chung, Andrew, Lawrence Hurley, Jackie Botts, Andrea Januta, and Guillermo Gomez. 2020. "For Cops Who Kill , Special Supreme Court Protection." Reuters. 2020.

https://www.reuters.com/investigates/specialreport/usa-police-immunity-scotus/.

Çil, Habib, Z. A. Atilgan, Y. Islamoglu, E. O. Tekbas, and Z. Dostbil. 2012. "Is the Pepper Spray a Triggering Factor in Myocardial Infarction? A Case Report." European Review for Medical and Pharmacological Sciences 16 (SUPPL. 1): 73-74.

Conteras, Oscar. 2020. "Judge Puts Strong Restriction on Denver Police Use of Tear Gas, Pepper Balls during Protests." The Denver Channel, June 5, 2020.

https://www.thedenverchannel.com/news/front -range/denver/judge-puts-strong-restrictionson-denver-police-use-of-tear-gas-pepper-ballsduring-protests

"Customary IHL - Practice Relating to Rule 75 . Riot Control Agents." 1993. 1993. https://ihldatabases.icrc.org/customaryihl/eng/print/v2 rul rule75.

Czarnecki, Fabrice. 2003. "Chemical Hazards in Law Enforcement." Clinics in Occupational and Environmental Medicine 3 (3): 443-56. https://doi.org/10.1016/S1526-0046(03)00075$\underline{\mathrm{X}}$. 
Dagli, E., E. Uslu, G. Ozkan, F. Uyanusta Kucuk, H. Onaran, C. Tastan Uzunmehmetoglu, A. Ilgaz, et al. 2014. "Respiratory Effects of Tear Gas Exposure." https://www.atsjournals.org/doi/abs/10.1164/a jrccmconference.2014.189.1 MeetingAbstracts.A3142.

Diaz, Adrian. 2020a. "8.100 - De-Escalation - Police Manual." Seattle Police Department Manual. 2020. https://www.seattle.gov/policemanual/title-8---use-of-force/8100---deescalation.

Diaz, Adrian. 2020b. "8.100 - De-Escalation - Police Manual." Seattle Police Department Manual. 2020.

Dimitroglou, Yiannis, George Rachiotis, and Christos Hadjichristodoulou. 2015. "Exposure to the Riot Control Agent CS and Potential Health Effects: A Systematic Review of the Evidence." International Journal of Environmental Research and Public Health 12 (2): 1397-1411. https://doi.org/10.3390/ijerph120201397.

"DOJ OIG Announces Initiation of Work." 2020. https://oig.justice.gov/news/doj-oig-announcesinitiation-work.

Feigenbaum, Anna. 2018. "The Man Behind the Mask." Jacobin Magazine, 2018.

https://www.jacobinmag.com/2018/01/teargas-policing-anna-feigenbaum.

Feigenbaum, Anna. 2020. "How Tear Gas Became the White Supremacist's Favorite Poison." Mother Jones Daily, June 8, 2020.

https://www.motherjones.com/crimejustice/2020/06/tear-gas-history-racistsuppression/.

Fowers, Alyssa, Aaron Steckelberg, and Bonnie Berkowitz. 2020. "A Guide to the Less-Lethal Weapons That Law Enforcement Uses against Protesters." The Washington Post, June 5, 2020. https://www.washingtonpost.com/nation/2020 106/05/less-lethal-weaponsprotests/?arc404=true.

Glynn, Kelly. 2020. "FDA Authorizes First-of-Its-Kind, Low-Cost Ventilator Developed by University of Minnesota." 2020.

Goyette v. City of Minneapolis, Case No. 20-cv-1302 (WMW/DTS) (D. Minn. Jun. 9, 2020)

Griffith, Janelle. 2021. "New York Attorney General Sues NYPD to Install Monitor, Alleges Years of Civil Rights Abuses." https://www.nbcnews.com/news/nbcblk/newyork-attorney-general-sues-nypd-install-federalmonitor-alleges-n1254288.

Guerra, Arnaldo Perez. 2009. "Tear Gas Dangers: The Toxic Cloud of Carabineros." Punto Final, August 7, 2009. www.puntofinal.cl/691/nube.php.
Haar, Rohini J., Vincent Iacopino, Nikhil Ranadive, Madhavi Dandu, and Sheri D. Weiser. 2017. "Death, Injury and Disability from Kinetic Impact Projectiles in Crowd-Control Settings: A Systematic Review." BMJ Open 7 (12): 1-9. https://doi.org/10.1136/bmjopen-2017-018154.

Haar, Rohini J., Vincent Iacopino, Nikhil Ranadive, Sheri D. Weiser, and Madhavi Dandu. 2017. "Health Impacts of Chemical Irritants Used for Crowd Control: A Systematic Review of the Injuries and Deaths Caused by Tear Gas and Pepper Spray." BMC Public Health 17 (1): 1-14. https://doi.org/10.1186/s12889-017-4814-6.

Habanero, Detective. 2003. "A Short and Sordid History of Pepper Spray.” Nopepperspray.Org. 2003. http://www.nopepperspray.org/sordid.htm.

Hambling, David. 2009. "Pain Ray' First Commercial Sale Looms." Wiired, August 5, 2009. https://www.wired.com/2009/08/pain-rayfirst-commercial-sale-looms/.

Harlow v. Fitzgerald, 457 U.S. 800 (1982)

Hayman, Mari. 2011a. "Chile Suspends Use of Tear Gas Amid Concerns Over Miscarriages." Latin Dispatch, May 19, 2011.

https://latindispatch.com/2011/05/19/chilesuspends-use-of-tear-gas-amid-concerns-overmiscarriages/.

Hayman, Mari. 2011b. "Chilean Government Resumes Use of Tear Gas As HidroAysén Protests Continue." Latin Dispatch, May 25, 2011. https://latindispatch.com/2011/05/25/chileangovernment-resumes-use-of-tear-gas-ashidroaysen-protests-continue/gas/.

Hiatt, Fred. 1987. "American Doctors Criticize Use of Tear Gas by South Korean." The Washington Post, July 1987.

https://www.washingtonpost.com/archive/polit ics/1987/07/23/american-doctors-criticize-useof-tear-gas-by-south-korean-police/6dbe1455aaf1-4a7d-8973-24f3ba9f1a4a/.

Hout, Joseph J., Duvel W. White, Anthony R. Artino, and Joseph J. Knapik. 2014. "O-Chlorobenzylidene Malononitrile (CS Riot Control Agent) Associated Acute Respiratory Illnesses in a U.S. Army Basic Combat Training Cohort." Military Medicine 179 (7): 793-98. https://doi.org/10.7205/MILMEDD-13-00514.

Hu, H. 1989. "Tear Gas--Harassing Agent or Toxic Chemical Weapon?" JAMA: The Journal of the American Medical Association 262 (5): 660-63. https://doi.org/10.1001/jama.262.5.660. 
Ilgaz, Aslıhan, Filiz Çağla Küçük Uyanusta, Peri Arbak, Arif Müezzinoğlu, Tansu Ulukavak Çiftçi, Serdar Akpınar, Hikmet Firat, et al. 2019. "Extensive Exposure to Tear Gases in Ankara." Turkish Thoracic Journal 20 (2): 108-13. https://doi.org/10.5152/TurkThoracJ.2018.1809 $\underline{6}$.

Jacoby, Kenny. 2019. "Police Use of Force Data ' a Huge Mess ' Across." The Register-Guard, August 25, 2019.

https://www.registerguard.com/news/2019082 5/police-use-of-force-data-a-huge-mess-acrossus.

Jameson, Sam. 1987. “Korea Studen'ts Death Sparks Clash in Seoul: Police Disperse Demonstration With Tear Gas; Protesters Spurn Ruling Party's Condole." Los Angeles Times, July 6, 1987. https://www.latimes.com/archives/la-xpm1987-07-06-mn-1311-story.html.

Johnsen, Bjorn A, Jan H Blanch, Synnove Lyngaas, Erling Odden, and Ulf R Syversen. 1985. "Analysis of Snow Samples Contaminated with Chemical Warfare Agents - Part 4."

Jones, Daniel P. 1978. "From Military to Civilian Technology: The Introduction of Tear Gas for Civil Riot Control." Technology and Culture 19 (2): 151-68. https://www.jstor.org/stable/3103718.

Kamb, Lewis. 2020. "How Ambiguity and a Loophole Undermined Seattle's Ban on Tear Gas during George Floyd Demonstrations." Seattle Times, June 9, 2020.

https://www.seattletimes.com/seattlenews/how-ambiguity-and-a-loopho...

Karagama, Y. G., J. R. Newton, and C. J.R. Newbegin. 2003. "Short-Term and Long-Term Physical Effects of Exposure to CS Spray." Journal of the Royal Society of Medicine 96 (4): 172-74. https://doi.org/10.1258/irsm.96.4.172.

Kaske, Erika A., Samuel W. Cramer, Isabela Pena Pino, Truong H. Do, Bryan M. Ladd, Dylan T. Sturtevant, Aliya Ahmadi, et al. 2021. "Injuries from LessLethal Weapons during the George Floyd Protests in Minneapolis." New England Journal of Medicine, 1-2.

https://doi.org/10.1056/nejmc2032052.

Kearney, Thomas, Patricia Hiatt, Elisabeth Birdsall, and Craig Smollin. 2014. "Pepper Spray Injury Severity: Ten-Year Case Experience of a Poison Control System." Prehospital Emergency Care 18 (3): 381-86. https://doi.org/10.3109/10903127.2014.89106 $\underline{3}$.
Keller, William C., Robert G. Elves, and John C. Bonnin. 1986. "Assessment of CS Environmental Toxicity at Eglin AFB FL." USAFOEHL Report.

Kenny, John M, Marvin Ziskin, Bob Adair, Bosseau Murray, Donald Farrer, Lawrence Marks, and Viktor Bovbjerg. 2008. "A Narrative Summary and Independent Assessment of the Active Denial System."

Kim, Sangseong, and Sun Wook Hwang. 2013. "Emerging Roles of TRPA1 in Sensation of Oxidative Stress and Its Implications in Defense and Danger." Archives of Pharmacal Research. Arch Pharm Res. https://doi.org/10.1007/s12272-013-0098-2.

Kirby, Jen. 2020. “The 'Kettling' of Protesters , Explained." Vox, June 6, 2020. https://www.vox.com/2020/6/6/21282509/geo rge-floyd-protests-kettling-new-york-nypd.

Krause, Kevin. 2001. "TEAR GAS STARTED PHARMACY FIRE, REPORT SAYS." South Florida Sun-Sentinel, March 30, 2001. https://www.sunsentinel.com/news/fl-xpm-2001-05-300105300347-story.html.

Kroman, David. 2020. “Judge Blocks Seattle's Ban on Tear Gas, Other Crowd Control Weapons." Crosscut.Com. 2020. https://crosscut.com/2020/07/judge-blocksseattles-ban-tear-gas-other-crowd-controlweapons.

Lagoe, A.J., and Steve Eckert. 2020. "KARE 11 Investigates : State Refuses to Identify Weapons Used against Protesters." KARE 11, June 10, 2020. https://www.kare11.com/article/news/local/ge orge-floyd/kare-11-investigates-state-refuses-toidentify-weapons-used-against-protesters/89f84b25d8-d

Lai, By K K Rebecca, Bill Marsh, and Anjali Singhvi. 2020. "Here Are the 100 U. S . Cities Where Protesters Were Tear-Gassed." The New York Times, June 18, 2020.

https://www.nytimes.com/interactive/2020/06 $\not 16 /$ us/george-floyd-protests-police-teargas.html.

Lunsford, Mackensy. 2020. 'Senseless' and 'Wrong':

North Carolina Mayor Condemns Police

Destruction of Medics' Tent." USA Today, June 4, 2020.

https://www.usatoday.com/story/news/nation/ 2020/06/04/asheville-police-destroy-medicarea-mayor-calls-actionssenseless/3148803001/.

Marcou, Dan. 2011. "The 'Madison Method' for Crowd Control." PoliceOne.Com. https://www.policeone.com/crowdcontrol/articles/the-madison-method-for-crowdcontrol-M2eLulyuo4QjtsWA/. 
Mashek, Kera. 2020. “KC Man Seriously Injured during Weekend Protests after Leg Takes Direct Hit from Tear Gas Canister." Fox News, June 1, 2020. https://fox4kc.com/news/kc-man-seriouslyinjured-during-weekend-protests-after-leg-takesdirect-hit-from-tear-gas-canister/.

Mayo Clinic. 2020. "Herd Immunity and COVID-19 (Coronavirus): What You Need to Know." June 2020. https://www.mayoclinic.org/diseasesconditions/coronavirus/in-depth/herdimmunity-and-coronavirus/art-20486808.

“Military Recruitment 2010." 2011. National Priorities Project. 2011.

https://www.nationalpriorities.org/analysis/201 1/military-recruitment-2010/.

Morrison, Billy W., D. Dralle, and K. Demaree. 1974. "Effects of CS Agents on Vegetation: II. Field and Screening Studies."

Nathan, Rajan, Harry Wood, Keith Rix, and Eric Wright. 2003. "Long-Term Psychiatric Morbidity in the Aftermath of CS Spray Trauma." Medicine, Science and the Law 43 (2): 98-104. https://doi.org/10.1258/rsmmsl.43.2.98.

Ness, Lindsey Van. 2020. "Tear Gas Bans : A Policing Change Not Gaining Traction." The Pew Charitable Trusts, August 4, 2020. https://www.pewtrusts.org/en/research-andanalysis/blogs/stateline/2020/08/04/tear-gasbans-a-policing-change-not-gaining-traction.

New York Times. 1995. "A . C . L . U . Report Calls Pepper Spray Potentially Deadly," June 19, 1995.

O'Connor, Terence M., Joseph O'Connell, Darren I. O'Brien, Triona Goode, Charles P. Bredin, and Fergus Shanahan. 2004. "The Role of Substance P in Inflammatory Disease." Journal of Cellular Physiology. John Wiley \& Sons, Ltd. https://doi.org/10.1002/icp.20061.

Olajos, Eugene J., and Harry Salem. 2001a. "Riot Control Agents: Pharmacology, Toxicology, Biochemistry and Chemistry." Journal of Applied Toxicology 21 (5): 355-91. https://doi.org/10.1002/jat.767.

Olajos, Eugene J., and Harry Salem .2001b. "Riot Control Agents: Pharmacology, Toxicology, Biochemistry and Chemistry." Journal of Applied Toxicology 21 (5): 355-91. https://doi.org/10.1002/jat.767.

Protocol for the Prohibition of the Use in War of Asphyxiating, Poisonous or Other Gases, and of Bacteriological Methods of Warfare (Geneva Protocol). 1925. Bureau of International Security and Nonproliferation. https://doi.org/10.2307/2212913.

Ranney, Megan L., Valerie Griffeth, and Ashish K. Jha. 2020. "Critical Supply Shortages - The Need for Ventilators and Personal Protective Equipment during the Covid-19 Pandemic." New England Journal of Medicine 41 (1): 1-2. https://doi.org/10.1056/NEJMp2009027.
Reid Moir, A. 1922. "Gas as a Humane Weapon; Protests From Sufferers Against Rear Admiral Sims's Theory." The New York Times, July 30, 1922. https://nyti.ms/1kGfjwo.

Richardson, Safiya, Jamie S. Hirsch, Mangala Narasimhan, James M. Crawford, Thomas McGinn, Karina W. Davidson, Douglas P. Barnaby, et al. 2020. "Presenting Characteristics, Comorbidities, and Outcomes among 5700 Patients Hospitalized with COVID-19 in the New York City Area." JAMA - Journal of the American Medical Association 323 (20): 2052-59. https://doi.org/10.1001/jama.2020.6775.

Riski, Tess. 2020a. "Hours After Gov. Kate Brown Signs Tear Gas Ban Into Law, Portland Police Deploy More Gas Onto Protesters." Wweek.Com. 2020. https://www.wweek.com/news/2020/07/01/h ours-after-gov-kate-brown-signs-tear-gas-baninto-law-portland-police-deploy-more-gas-ontoprotesters/.

Riski, Tess 2020b. "When Police Deploy Tear Gas on Protesters, It Leaks Into the Homes of Portlanders." Willamette Week, July 8, 2020. https://www.wweek.com/news/2020/07/08/w hen-police-deploy-tear-gas-on-protesters-itleaks-into-the-homes-of-portlanders/.

Rivas, Kayla. 2020. “Tear Gas, Projectile Canisters Can Pose Serious Injury, Experts Say." Fox News, June 2, 2020. https://www.foxnews.com/health/teargas-projectile-can-pose-serious-injury-expertssay.

Rothenberg, Craig, Satyanarayana Achanta, Erik R. Svendsen, and Sven Eric Jordt. 2016a. "Tear Gas: An Epidemiological and Mechanistic

Reassessment." Annals of the New York Academy of Sciences 1378 (1): 96-107. https://doi.org/10.1111/nyas.13141.

Rothenberg, Craig, Satyanarayana Achanta, Erik R. Svendsen, and Sven Eric Jordt. 2016b. "Tear Gas: An Epidemiological and Mechanistic

Reassessment." Annals of the New York Academy of Sciences 1378 (1): 96-107. https://doi.org/10.1111/nyas.13141.

Ruan, Qiurong, Kun Yang, Wenxia Wang, Lingyu Jiang, and Jianxin Song. 2020. "Clinical Predictors of Mortality Due to COVID-19 Based on an Analysis of Data of 150 Patients from Wuhan, China." Intensive Care Medicine 46 (5): 846-48. https://doi.org/10.1007/s00134-020-05991-x.

"Safety Data Sheet - CS Pellets." 2013. http://sds.chemtel.net/webclients/safariland/fin ished goods/Defense $\% 20$ Technology $\% 201698 \%$ 20-\%20CS\%20Pellets.pdf

"Safety Data Sheet - First Defense Stream OC Aerosol." 2018. 
"Safety Data Sheet - Potassium Chlorate, Lab Grade." 2015. https://betastatic.fishersci.com/content/dam/fishersci/en_U S/documents/programs/education/regulatorydocuments/sds/chemicals/chemicalsp/S25482.pdf.

"Safety Data Sheet - WEST SYSTEM 105 Epoxy Resin." 2019. https://www.westsystem.com/wpcontent/uploads/105-SDS.pdf.

Sawyer, Liz, and Libor Jany. 2020. "Complaints Skyrocket over Police Response to George Floyd Protests." Star Tribune, July 2, 2020. https://www.startribune.com/complaintsskyrocketing-in-wake-of-mpls-police-responseto-floyd-protests/571608232/.

Schep, Leo J., R. J. Slaughter, and D. I. McBride. 2013a. "Riot Control Agents: The Tear Gases CN, CS and OC-a Medical Review." Journal of the Royal Army Medical Corps 161 (2): 94-99. https://doi.org/10.1136/jramc-2013-000165.

Schep, Leo J., R. J. Slaughter, and D. I. McBride. 2013b. "Riot Control Agents: The Tear Gases CN, CS and OC-a Medical Review." Journal of the Royal Army Medical Corps 161 (2): 94-99. https://doi.org/10.1136/iramc-2013-000165.

Schuhmacher, Tracy. 2020. "We Know about Injuries to Rochester Police Sept. 5. What about Injuries to Protesters?" Rochester Democrat and Chronicle, September 11, 2020.

https://www.democratandchronicle.com/story/ news/2020/09/11/how-many-injuriesprotesters-sept-5-2020-rochesterny/3466996001/.

Seattle City Council - Record No: CB 118310. 2015. City of Seattle.

http://seattle.legistar.com/LegislationDetail.aspx ?ID=2164447\&GUID=4F61DD1B-B76C-4CA7BB57-C9266E0F96DB.

Selsky, Andrew. 2020. "Lack of Study and Oversight Raises Concerns about Tear Gas." Associated Press, August 6, 2020.

https://apnews.com/c814cc7b873ccaf60b95b10 e96ecfc12.

Smith, Emily. 2011. "Controversial Tear Gas Canisters Made in the USA." CNN, January 28, 2011. http://edition.cnn.com/2011/WORLD/africa/01 28/egypt.us.tear.gas/

Sobel, Nathaniel. 2020. "What Is Qualified Immunity, and What Does It Have to Do With Police Reform?" Lawfare. 2020. http://www.chicagoasthma.org/ige-asthmascientific-version/.
Song, Lisa. 2020. "Tear Gas Is Way More Dangerous Than Police Let On - Especially During the Coronavirus Pandemic." ProPublica, June 4, 2020. https://www.propublica.org/article/tear-gas-isway-more-dangerous-than-police-let-onespecially-during-the-coronavirus-pandemic.

Taylor, Derrick Bryson. 2020. "George Floyd Protests:" The New York Times, July 10, 2020.

https://www.nytimes.com/article/george-floydprotests-timeline.html.

"Tear Gas - Stuff You Missed in History Class." 2020. Stuff You Missed in History Class. 2020. https://www.happyscribe.com/public/stuff-youmissed-in-history-class/tear-gas.

Temple-Raston, Dina. 2020. "Protesters Were Supposed To Hear Warnings Before Federal Police Moved In. They Didn't." National Public Radio, September 11, 2020. https://www.npr.org/2020/09/11/911912921/ protesters-were-supposed-to-hear-warningsbefore-federal-police-moved-in-they-di.

“The Institutional Animal Care and Use Committee." 2015. National Institutes of Health. 2015. https://doi.org/10.1016/B978-0-12-4200586.00003-4.

The New York Times. 1996. "Former F.B.I. Agent Is Sentences to Prison," May 20, 1996. https://www.nytimes.com/1996/05/20/us/for mer-fbi-agent-is-sentenced-to-prison.html

The Pittsburgh Press. 1988. "U.N. Says Israeli Use of Tear Gas Caused Miscarriages, 11 Deaths," June 1, 1988.

"The Use of Tear Gas in the Republic of Korea: A Report by Health Professionals." 1987.

Tidwell, R. David, and Brandon K. Wills. 2019. "Tear Gas (Pepper Spray) Toxicity." StatPearls, 1-7. http://www.ncbi.nlm.nih.gov/pubmed/3133498 3.

Toprak, Sadik, Gokhan Ersoy, John Hart, and Peter Clevestig. 2015. "The Pathology of Lethal Exposure to the Riot Control Agents: Towards a Forensics-Based Methodology for Determining Misuse." Journal of Forensic and Legal Medicine 29: 36-42. https://doi.org/10.1016/i.jflm.2014.11.006.

Totenberg, Nina. 2020. "Supreme Court Weighs Qualified Immunity for Police Accused of Misconduct." National Public Radio, June 8, 2020. https://www.reuters.com/investigates/specialreport/usa-police-immunity-scotus/.

"United States of America : Ratification of 1925 Geneva Protocol." 1975. United Nations Office for Disarmament Affairs. 1975. http://disarmament.un.org/treaties/a/1925/uni tedstatesofamerica/rat/paris. 
Unuvar, Umit, Onder Ozkalipci, Sukran Irencin, Umit Sahin, and Sebnem Korur Fincanci. 2013.

"Demonstration Control Agents: Evaluation of 64 Cases after Massive Use in Istanbul." American Journal of Forensic Medicine and Pathology 34 (2): $150-54$. https://doi.org/10.1097/PAF.0b013e3182887b3 c.

Waters, Brian. 2019a. "Denver Police Chemical Weapons Materials Safety Data Sheets (MSDS)." MuckRock. 2019. https://www.muckrock.com/foi/denver145/denver-police-chemical-weapons-materialssafety-data-sheets-msds-68204/.

Waters, Brian. 2019b. "Denver Police Chemical Weapons Materials Safety Data Sheets (MSDS)." MuckRock. 2019.

Wheeler, H., R. MacLehose, E. Euripidou, and V. Murray. 1998. "Surveillance into Crowd Control Agents." The Lancet 352 (9132): 991-92. https://doi.org/10.1016/S0140-6736(05)61550$\underline{4}$.

Williams, Natasha, Maija Fiorante, Vincent Wong, Ashley Major, and Petra Molnar. 2020. "The Problematic Legality of Tear Gas Under International Human Rights Law." https://ihrp.law.utoronto.ca/.
Wood, Lesley. 2020. "Policing Counter-Protest." Sociology Compass 14 (11): 1-10. https://doi.org/https://doi.org/10.1111/soc4.12 833.

Worthley, Elmer G. 1971. The Comparative Effects of CS and Various Pollutants on Fresh Water Phytoplankton Colonies of Wolffia Papulitera Thompson. PN.

Yang, Hang, and Shu Zhuang Li. 2016. "Transient Receptor Potential Ankyrin 1 (Trpa1) Channel and Neurogenic Inflammation in Pathogenesis of Asthma." Medical Science Monitor. International Scientific Literature Inc. https://doi.org/10.12659/MSM.896557.

Zakhama, Lilia, Wassim Ben Ameur, Saoussen Antit, Iskander Slama, Alaa Eddine Jallad, Sara Chenik, Mourad Masmoudi, et al. 2016. "Can CS Gas Induce Myocardial Infarction?" Tunisie Medicale 94 (10): 626-28.

Zekri, A. M.B., W. W.K. King, R. Yeung, and W. R.J. Taylor. 1995. "Acute Mass Burns Caused by 0Chlorobenzylidene Malononitrile (CS) Tear Gas." Burns 21 (8): 586-89. https://doi.org/10.1016/0305-4179(95)00063$\underline{\mathrm{H}}$.

Jennifer L. Brown is a Dual-Neuroscience $\mathrm{PhD}$ candidate and J.D. candidate at the University of Minnesota. Her research focuses on the molecular mechanisms of neurodegenerative diseases such as Alzheimer's and Parkinson's, with a focus on the biological variable of sex. Jennifer is interested in the confluence of law and science, in how science is used in the legal system and in how policy can be used as a tool to foster equity and justice.

Carey E. Lyons is a PhD candidate in Neuroscience at the University of Minnesota, where her research interrogates the interaction of stress and aging. She is deeply invested in the role of scientific research and its interpretation in informing public policy. She is also a native of Tacoma, Washington where in 1935, the first domestic use of tear gas occurred when the National Guard used it against timber workers striking to gain union recognition.

Carlee Toddes is a Neuroscience PhD candidate at the University of Minnesota, where she studies the neural circuitry underlying affiliative social behavior. Her current research involves elucidating the role of mu opioid receptors in regulating social behavioral expression in mice. Carlee is passionate about the intersection of science and policy and the utilization of research to inform policies that lead to equitable changes in governance.

Timothy Monko is a $\mathrm{PhD}$ candidate in Neuroscience at the University of Minnesota, where he studies the developing brain. His current work investigates the intersection of neural and immune cells during development of brain sensory areas, so he is particularly concerned by the threat tear gas poses to vulnerable children and pregnant women looking to exercise free speech. Tim hopes to continue into academic science where he can mentor the next generation to be passionate about both science and social justice.

Roman Tyshynsky is a Neuroscience PhD candidate at the University of Minnesota, where he studies the sensory nerves of the kidneys. Part of his research involves investigating the role TRPV1 channels in renal function- the same channels that are affected by compounds in many DCAs. Roman hopes to continue to use 
his scientific background to help affect change and hopes to have a career in the development of biomedical devices for the treatment of nervous system conditions.

Acknowledgements: We would like to extend our sincerest gratitude to our friend and classmate Maria Linn-Evans for providing valuable feedback. We would also like to extend our gratitude to Wilella Burgess and Barbara Toddes for their editorial assistance. 